\title{
Age related Anatomical Changes in Acetabulum and its Cartilage in Buffalo (Bubalus bubalis)
}

\author{
Ranjith Kumar Sundari ${ }^{1 *}$, Pramod Kumar Damaraju1, Purushotham Gudepu², \\ Lakshman Mekala ${ }^{3}$ and E.L. Chandrashekhar ${ }^{4}$ \\ ${ }^{1}$ Department of Veterinary Anatomy. College of Veterinary Science, Rajendranagar, Hyderabad, INDIA \\ ${ }^{2}$ Department of Veterinary Anatomy, College of Veterinary Science, Mamnoor, Warangal, INDIA \\ ${ }^{3}$ Department of Veterinary Pathology, College of Veterinary Science, Rajendranagar, Hyderabad, INDIA \\ ${ }^{4}$ Teaching Veterinary Clinical Complex, College of Veterinary Science, Rajendranagar, Hyderabad, INDIA \\ *Corresponding author: RK Sundari; E-mail:varma.dr@gmail.com
}

Received: 10 Aug., 2021

Revised: 02 Sept., 2021

Accepted: 08 Sept., 2021

\begin{abstract}
Acetabular articular cartilage was not differentiated in prenatal group. Acetabular AC in post natal groups was well differentiated and continuous on anterio-lateral and caudo-lateral aspects i.e., towards ilium and ischium respectively, whereas at medial part i.e., towards pubis it was separated on either side. Mean AC thickness of acetabulum at three points showed slight variation. Overall average width of acetabular AC increased with age viz., $23.85 \mathrm{~mm}$ to $28.95 \mathrm{~mm}$ in Gr- IV, whereas the dimensions of acetabulum like the diameter and depth revealed a steady increase with advancing age. In Gr-I they were $0.35 \mathrm{~cm}$ and $0.4 \mathrm{~cm}$ which increased up to $5.38 \mathrm{~cm}$ and $4.11 \mathrm{~cm}$ in $\mathrm{Gr}$ - IV respectively. Irregular erosions towards centre of acetabulum were seen on AC surface in aged specimens of groups III and IV.
\end{abstract}

\section{HIGHLIGHTS}

(0 Variation in the articular cartilage morphology with the age in Buffaloes

(- Variation in the thickness and cartilage width of $\mathrm{AC}$ acetabulum with the age in Buffaloes.

0 Variation in diameter and depth of the acetabulum with the age

Keywords: Articular cartilage, Acetabulum, Buffalo

The acetabulum has a 'C'-shaped articular surface, the lunate surface, which is lined by hyaline cartilage. The rim of the acetabulum is lined with a fibrocartilagenous acetabular labrum, part of which bridges across the acetabular notch as the transverse acetabular ligament. Heavily lined articular cartilage is the only part of the acetabulum that normally contacts with the femoral head. Articular cartilage plays an important role in joint diseases especially in osteoarthritis where there are specific changes in it and also its repair and remodelling (Taylor et al., 2011). In the literature reviewed so far most of the research work was on femoral head but there was very little work on the acetabulum both in humans and animals. Therefore present study on the $\mathrm{AC}$ of acetabulum gives an idea about the aging changes in the thickness and appearance of articular cartilage in buffaloes.

\section{MATERIALS AND METHODS}

The present investigation was carried out in the Department of Veterinary Anatomy, College of Veterinary Science, Rajendranagar, Hyderabad. Intact hip joint specimens of twenty four (24) apparently healthy buffaloes irrespective

How to cite this article: Sundari, R.K., Damaraju, P.K., Gudepu, P., Mekala, L. and Chandrashekhar, E.L. (2021). Age related Anatomica Changes in Acetabulum and its Cartilage in Buffalo (Bubalus bubalis). J. Anim. Res., 11(05): 857-861.

Source of Support: None; Conflict of Interest: None क्ष 
of their breed, sex and nutritional status were procured from GHMC Modern Abbattoir, Chengicherla and local slaughter houses in and around Hyderabad. Collected specimens were divided into two primary groups viz., one Prenatal stage - Group I (as per the formula of Soliman, 1975) and three Post natal stages as per their approximate age based on dentition pattern by FAO (1994) such as Group II (neonatal), Group III (young adult) and Group IV (aged). Samples were collected from both hind limbs by separating hip joint by dissecting the joint and cutting the round ligament and acetabula were secured. Acetabulum specimens of all groups were carefully dissected to study gross anatomical surface features of articular cartilages (AC) of acetabulum in all age groups. Immediately various gross morphological features were studied, noted and photographed accordingly. Morpho-metrical details as detailed below were recorded with a thread, scale and digital Vernier caliper's (Mitutoyo) which ever was necessary:

1. The average thickness of AC of acetabulum was taken from various points.

2. The average width of $\mathrm{AC}$ of acetabulum (i.e., the lunate shaped AC).

3. Average diameter measured at various points and also the depth (as per Khobragade nd Vatsalaswamy 2017) of acetabulum.

\section{RESULTS AND DISCUSSION}

In the present study, the acetabulum in prenatal group $(\mathrm{Gr}-\mathrm{I})$ was fully cartilaginous with a cup like depression comprising an articular and non-articular area. AC was not yet differentiated in this stage yet the articular surface area of acetabulum was increased due to presence of acetabular labrum on its margin to accommodate the entire hemispherical femoral head (Fig. 1). Similar observations were made by Dyce et al. (2010) in domestic animals who reported that acetabular surface was enlarged by an articular labrum. Two areas of acetabulum seen in this study were also reported by Supriya et al. (2014) in buffalo calves who stated that acetabulum consisted of an articular part facies lunata and non-articular part the acetabular fossa. They further stated that articular surface of acetabulum was semilunar in shape and its margin was notched, both of which were true in this study.
In groups II, III and IV the acetabulum was nearly circular in outline and its fossa was deeper than prenatal groups with a clear, well defined semi-lunar articular surface covered by distinct AC and bordered by a fibro-cartilagenous labrum (Fig. 2). These findings are in accordance with description of acetabulum in domestic animals by Dyce et al. (2010), Konig and Leibich (2012) and Supriya et al. (2014) who mentioned that the lunate articular surface covered by AC and bordered by fibro-cartilagenous labrum with a deep acetabular fossa are the main parts of acetabulum in hip joint of animals.

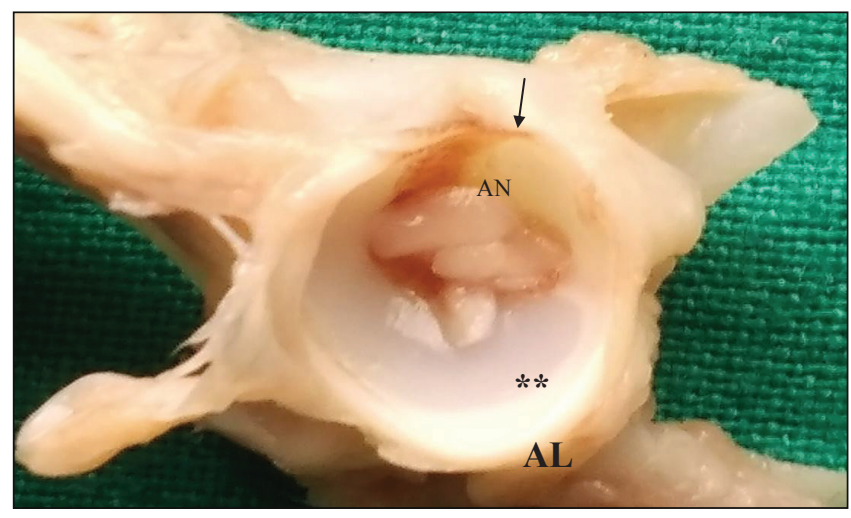

Fig. 1: Photograph of acetabulum showing AC (**), acetabular notch (AN), acetabular labrum (AL) and transverse acetabular ligament (black arrow) in 4 months old buffalo foetus (Group-I)

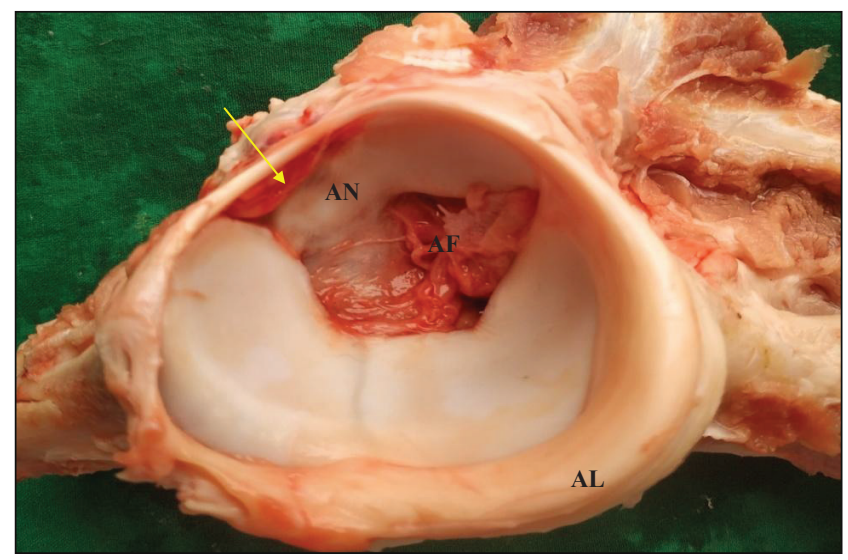

Fig. 2: Photograph of acetabulum showing $A C$, acetabular notch (AN), acetabular fossa (AF), acetabular labrum (AL) and transverse acetabular ligament (linearrow) in Group-II specimen (approximately aged 2.5 years)

In post natal groups the acetabular $\mathrm{AC}$ was continuous on anterio-lateral and caudo-lateral aspects i.e., towards 
ilium and ischium respectively, whereas at medial part i.e., towards pubis it was small and separated on either side. Mean AC thickness of all three points taken showed slight variation viz., it decreased with advancing age (1.78 $\mathrm{mm}$ in Gr-II, $1.76 \mathrm{~mm}$ in $\mathrm{Gr}-\mathrm{III}$ and $1.64 \mathrm{~mm}$ in $\mathrm{Gr}-\mathrm{IV}$ specimens) (Table 1).

The AC width was more at ischial part followed by ilial and pubic parts. Overall average width of AC increased with age viz., $23.85 \mathrm{~mm}$ in $\mathrm{Gr}-\mathrm{II}, 28.08 \mathrm{~mm}$ in $\mathrm{Gr}-\mathrm{III}$ and $28.95 \mathrm{~mm}$ in Gr- IV specimens (Table 2). Whereas, in European bison Kobrynczuk (1976) stated that acetabular $\mathrm{AC}$ was $1.8 \mathrm{~mm}$ thick in pars minor, up to $2.4 \mathrm{~mm}$ in pars major of fetuses and newborns and $0.9 \mathrm{~mm}$ in both parts of adults. Shepherd and Seedhom (1999) compared the thickness in different parts of human acetabula i.e., in superior, anterior and posterior areas and they recorded that variation ranged from 1.24 to $2.25 \mathrm{~mm}, 1.2$ to 1.71 $\mathrm{mm}$ and 1.24 to $1.85 \mathrm{~mm}$ respectively.

Table 1 results state that $\mathrm{AC}$ thickness is slightly variable with advancing age in human acetabula which was appreciated in the acetabulum of buffalo specimens examined in this investigation, wherein the $\mathrm{AC}$ thickness showed a decreasing trend with advancement of age. Dimensions of acetabulum revealed a steady increase in size with advancing age. In Gr-I the average diameter and depth of acetabulum was $0.35 \mathrm{~cm}$ and $0.4 \mathrm{~cm}$ which increased steadily up to $5.38 \mathrm{~cm}$ and $4.11 \mathrm{~cm}$ in $\mathrm{Gr}-\mathrm{IV}$ (Table 3).

The anatomical construction of acetabulum helps to firmly hold the head of femur which in turn will provide biomechanical stability to hip joint to cater to its wide range of locomotion. Age related changes occurred on $\mathrm{AC}$ surface in later age groups i.e., in Gr III and IV specimens in this study. AC showed irregular erosions towards centre of acetabulum particularly anterio-lateral aspects of the fossa and also at peripheral part i.e., towards the labrum (Fig. 3). These signs may be due to lesser thickness nearer to acetabular fossa.

Table 1: Thickness of Articular Cartilage (AC) on Acetabulum

\begin{tabular}{|c|c|c|c|c|c|}
\hline \multirow{2}{*}{ Sl. No. } & \multicolumn{5}{|c|}{ Acetabular surface - Articular Cartilage thickness (in mm) } \\
\hline & Group & Pt. 1 (towards Ilium) & Pt. 2 (towards Ischium.) & Pt. 3 (towards Pubis) & Average (in mm) \\
\hline & $I(n=6)$ & AC not yet differentiated & - & - & - \\
\hline 1 & \multirow{6}{*}{ II $(n=6)$} & 1.47 & 1.77 & 2.16 & \multirow{6}{*}{$1.78 \mathrm{~mm}$} \\
\hline 2 & & 1.66 & 1.78 & 1.97 & \\
\hline 3 & & 1.74 & 1.73 & 1.82 & \\
\hline 4 & & 1.56 & 1.78 & 2.24 & \\
\hline 5 & & 1.42 & 1.69 & 1.99 & \\
\hline 6 & & 1.75 & 1.65 & 1.89 & \\
\hline 7 & \multirow{6}{*}{ III $(n=6)$} & 1.42 & 1.74 & 1.96 & \multirow{6}{*}{$1.76 \mathrm{~mm}$} \\
\hline 8 & & 1.77 & 1.75 & 2.07 & \\
\hline 9 & & 1.78 & 1.69 & 1.56 & \\
\hline 10 & & 1.56 & 1.82 & 1.99 & \\
\hline 11 & & 1.62 & 1.71 & 2.15 & \\
\hline 12 & & 1.69 & 1.68 & 1.75 & \\
\hline 13 & \multirow{6}{*}{$\mathrm{IV}(\mathrm{n}=6)$} & 1.49 & 1.44 & 1.56 & \multirow{6}{*}{$1.64 \mathrm{~mm}$} \\
\hline 14 & & 1.56 & 1.62 & 1.86 & \\
\hline 15 & & 1.61 & 1.59 & 1.78 & \\
\hline 16 & & 1.45 & 1.62 & 1.69 & \\
\hline 17 & & 1.54 & 1.68 & 1.87 & \\
\hline 18 & & 1.64 & 1.72 & 1.79 & \\
\hline
\end{tabular}


Table 2: Width of Acetabular AC in mm in three points of os coxae

\begin{tabular}{|c|c|c|c|c|c|}
\hline \multirow{2}{*}{ Sl. No. } & \multicolumn{5}{|c|}{ Acetabular surface - Articular Cartilage Width (in mm) } \\
\hline & Group & Pt. 1 (towards Ilium) & Pt. 2 (towards Ischium.) & Pt. 3 (towards Pubis) & Average (in mm) \\
\hline & $\mathrm{I}(\mathrm{n}=6)$ & AC not yet differentiated & - & - & - \\
\hline 1 & \multirow{6}{*}{$\mathrm{II}(\mathrm{n}=6)$} & 23.51 & 25.92 & 19.26 & \multirow{6}{*}{$23.85 \mathrm{~mm}$} \\
\hline 2 & & 20.15 & 22.8 & 17.1 & \\
\hline 3 & & 24.46 & 33.5 & 22.81 & \\
\hline 4 & & 21.84 & 25.48 & 20.12 & \\
\hline 5 & & 22.61 & 26.56 & 21.5 & \\
\hline 6 & & 24.52 & 34.02 & 23.2 & \\
\hline 7 & \multirow{6}{*}{$\begin{array}{l}\text { III } \\
(\mathrm{n}=6)\end{array}$} & 26.01 & 33.1 & 20.1 & \multirow{6}{*}{$28.08 \mathrm{~mm}$} \\
\hline 8 & & 29.03 & 32.3 & 24.6 & \\
\hline 9 & & 27.77 & 31.97 & 27.2 & \\
\hline 10 & & 30.25 & 32.6 & 22.8 & \\
\hline 11 & & 28.65 & 31.51 & 22.6 & \\
\hline 12 & & 29.41 & 31.9 & 23.9 & \\
\hline 13 & \multirow{6}{*}{$\begin{array}{l}\text { IV } \\
(n=6)\end{array}$} & 30.5 & 34.4 & 23.6 & \multirow{6}{*}{$28.95 \mathrm{~mm}$} \\
\hline 14 & & 30.62 & 32.86 & 20.27 & \\
\hline 15 & & 31.5 & 33.41 & 22.8 & \\
\hline 16 & & 31.8 & 31.8 & 23.9 & \\
\hline 17 & & 30.25 & 32.4 & 23.1 & \\
\hline 18 & & 32.15 & 33.1 & 22.6 & \\
\hline
\end{tabular}

Table 3: Morphometrical measurements of Acetabular cavity showing its diameter and depth Acetabular surface - Articular Cartilage diameter and depth in $\mathrm{cm}$

\begin{tabular}{|c|c|c|c|c|c|c|c|c|c|}
\hline \multirow{2}{*}{ Sl. No. } & \multicolumn{3}{|l|}{ Group } & \multicolumn{4}{|c|}{ Acetabular Diameter (in cm) } & \multirow{2}{*}{$\begin{array}{l}\text { Acetabular } \\
\text { Depth (in cm) }\end{array}$} & \multirow{2}{*}{$\begin{array}{l}\text { Avg. Value for } \\
\text { each group }\end{array}$} \\
\hline & $I(n=6)$ & Pt. 1 & Pt. 2 & Pt. 3 & Pt. 4 & Pt. 5 & Average value & & \\
\hline 1 & & 0.306 & 0.31 & 0.32 & 0.32 & 0.31 & \multirow{6}{*}{$0.35 \mathrm{~cm}$} & 0.29 & \multirow{6}{*}{$0.4 \mathrm{~cm}$} \\
\hline 2 & & 0.32 & 0.35 & 0.34 & 0.35 & 0.3 & & 0.32 & \\
\hline 3 & & 0.35 & 0.38 & 0.36 & 0.35 & 0.32 & & 0.38 & \\
\hline 4 & & 0.38 & 0.39 & 0.4 & 0.38 & 0.28 & & 0.5 & \\
\hline 5 & & 0.42 & 0.41 & 0.38 & 0.36 & 0.35 & & 0.42 & \\
\hline 6 & & 0.38 & 0.35 & 0.36 & 0.38 & 0.34 & & 0.49 & \\
\hline 7 & \multirow{6}{*}{$\mathrm{II}(\mathrm{n}=6)$} & 5.52 & 5.65 & 5.38 & 4.39 & 3.71 & \multirow{6}{*}{$4.74 \mathrm{~cm}$} & 3.67 & \multirow{6}{*}{$3.57 \mathrm{~cm}$} \\
\hline 8 & & 4.96 & 5.75 & 5.53 & 3.61 & 4.06 & & 3.78 & \\
\hline 9 & & 5.01 & 5.18 & 5.28 & 3.65 & 3.64 & & 3.41 & \\
\hline 10 & & 5.21 & 5.64 & 5.35 & 3.85 & 3.82 & & 3.59 & \\
\hline 11 & & 5.03 & 5.28 & 5.50 & 3.91 & 3.76 & & 3.35 & \\
\hline 12 & & 4.99 & 5.21 & 5.29 & 4.11 & 3.90 & & 3.60 & \\
\hline$\overline{13}$ & \multirow{6}{*}{$\mathrm{III}(\mathrm{n}=6)$} & 5.92 & 5.04 & 5.51 & 4.74 & 3.55 & \multirow{6}{*}{$4.83 \mathrm{~cm}$} & 3.95 & \multirow{6}{*}{$4.02 \mathrm{~cm}$} \\
\hline 14 & & 5.69 & 5.33 & 5.3 & 3.96 & 3.64 & & 3.99 & \\
\hline 15 & & 5.52 & 5.20 & 5.21 & 4.69 & 3.43 & & 3.97 & \\
\hline 16 & & 5.35 & 5.63 & 5.24 & 3.82 & 3.62 & & 4.12 & \\
\hline 17 & & 5.71 & 5.49 & 5.63 & 3.9 & 3.46 & & 3.86 & \\
\hline 18 & & 5.60 & 5.66 & 5.23 & 4.29 & 3.62 & & 4.22 & \\
\hline
\end{tabular}




\begin{tabular}{|c|c|c|c|c|c|c|c|c|c|}
\hline 19 & \multirow{6}{*}{$\operatorname{IV}(n=6)$} & 6.30 & 5.60 & 6.37 & 4.50 & 4.05 & \multirow{6}{*}{$5.38 \mathrm{~cm}$} & 3.99 & \multirow{6}{*}{$4.11 \mathrm{~cm}$} \\
\hline 20 & & 6.42 & 5.52 & 6.13 & 4.70 & 3.96 & & 4.28 & \\
\hline 21 & & 6.23 & 5.43 & 6.24 & 4.63 & 4.13 & & 4.38 & \\
\hline 22 & & 6.50 & 5.66 & 6.40 & 4.59 & 4.01 & & 3.89 & \\
\hline 23 & & 6.32 & 5.69 & 6.33 & 4.46 & 4.26 & & 3.98 & \\
\hline 24 & & 6.24 & 5.70 & 6.36 & 4.50 & 4.21 & & 4.11 & \\
\hline
\end{tabular}

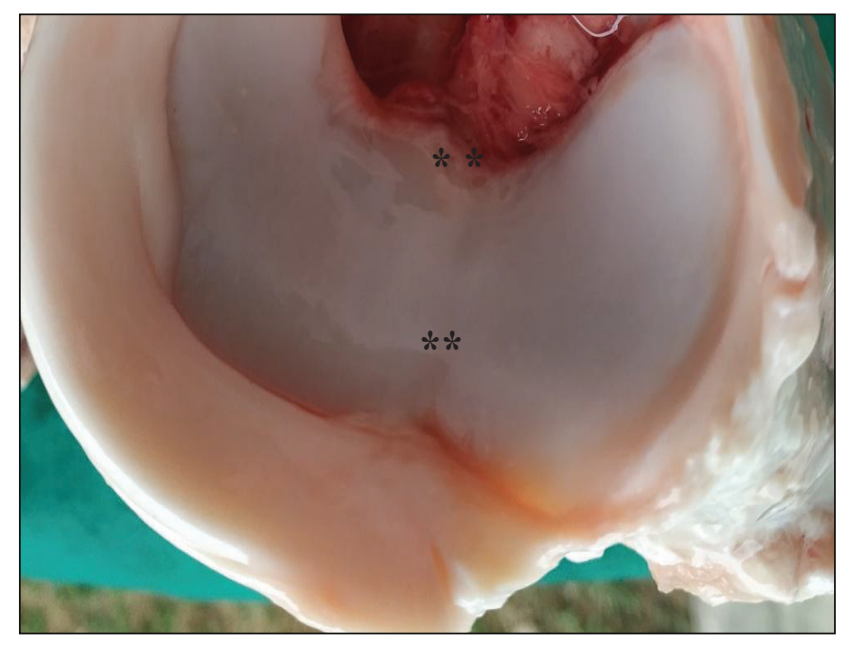

Fig. 3: Photograph showing eroded zones $(* *)$ at the peripheral part of AC in the acetabulum of Group-IV specimen (aged approximately 8.5 years)

\section{CONCLUSION}

Acetabular AC in post natal groups (II, III and IV) was continuous on anterio-lateral and caudo-lateral aspects i.e., towards ilium and ischium respectively, whereas at medial part i.e., towards pubis it was small and separated on either side. Mean AC thickness of acetabulum at three points showed slight variation. Overall average width of AC increased with age viz., $23.85 \mathrm{~mm}$ in $\mathrm{Gr}-\mathrm{II}, 28.08 \mathrm{~mm}$ in Gr - III and $28.95 \mathrm{~mm}$ in Gr- IV specimens. Dimensions of acetabulum revealed a steady increase with advancing age. In Gr-I the average diameter and depth of acetabulum was $0.35 \mathrm{~cm}$ and $0.4 \mathrm{~cm}$ which increased steadily up to $5.38 \mathrm{~cm}$ and $4.11 \mathrm{~cm}$ in $\mathrm{Gr}$ - IV. Age related changes occurred on AC surface in groups III and IV wherein the acetabular AC showed irregular erosions towards centre of acetabulum particularly anterio-lateral aspects of the fossa and at peripheral part i.e., towards the labrum.

\section{ACKNOWLEDGEMENTS}

I would place on record my gratitude towards P.V. Narsimha Rao Telangana Veterinary University, Hyderabad, for providing all the necessities during my investigation to prosecute my Doctorate studies.

\section{REFERENCES}

Dyce, K.M., Sac W.O. and Wensing C.J.G. 2010. Text book of Veterinary Anatomy, $4^{\text {th }}$ Edition. St. Louis, Saunders/ Elsevier, pp. 88 and 91.

FAO 1994. A Manual for Primary Animal Health Care Worker. Corporate Documentary Repository Chapter 3: Cattle, Sheep, Goats and Buffalo. Unit 9: How to age sheep, goats, cattle and buffalo, pp. 1-51.

Khobragade, L. and Vatsalaswamy, P. 2017. Morphometric study of depth of acetabulum. Int. J. Res. Sci., 5(9): 837-3842.

Kobrynczuk, F. 1976. Joints and Ligaments of hind limbs of the Europin Bison in its postnatal development. Acta Theriologica, 21(4): 37-100.

Konig, H.E. and Leibich, H.G. 2012. Text book and color atlas of Veterinary Anatomy of Domestic Mammals. Schattauer publisher, Stuttgart, New York, pp. 197-228.

Shepherd, D.E.T. and Seedhom, B.B. 1999. Thickness of human articular cartilage in joints of lower limb. Annals Rheu. Dis., 58: 27-34.

Soliman, M.K.1975. Studies on the physiological chemistry of allantoic and amniotic fluids of buffaloes at various periods of pregnancy. Indian Vet. J., 52: 106-112.

Supriya, B., Chandrasekhara Rao, T.S., Jagapathi Ramayya, P. and Suresh Kumar, R.V. 2014. Gross morphology of the hip articulation of buffalo calves (Bubalus bubalis). Int. J. Anatomy Res., 2(4): 645-49.

Taylor, S.D., Eleftherios, T., Ingham, E., Jin, Z., Fisher, J. and Williams, S. 2011. Comparison of human and animal femoral head chondral properties and geometries. Proceedings of Institute of Mechanical Engineers Part H: J. Engg. in Med., 226(1): 55-62. 
